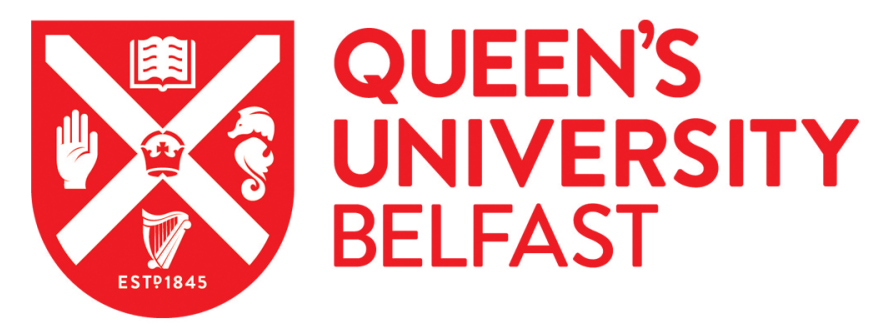

\title{
Role-related Stress and Perceptions of the Keyworker Role Among Professionals Supporting Adults with Intellectual Disabilities
}

Moriarty, J., Regan, D., \& Honan, R. (2019). Role-related Stress and Perceptions of the Keyworker Role Among Professionals Supporting Adults with Intellectual Disabilities. International Journal of Workplace Health Management, 12(4), 228-246. https://doi.org/10.1108/JWHM-06-2018-0077

Published in:

International Journal of Workplace Health Management

\section{Document Version:}

Peer reviewed version

Queen's University Belfast - Research Portal:

Link to publication record in Queen's University Belfast Research Portal

Publisher rights

Copyright 2019, Emerald.

This work is made available online in accordance with the publisher's policies. Please refer to any applicable terms of use of the publisher.

\section{General rights}

Copyright for the publications made accessible via the Queen's University Belfast Research Portal is retained by the author(s) and / or other copyright owners and it is a condition of accessing these publications that users recognise and abide by the legal requirements associated with these rights.

Take down policy

The Research Portal is Queen's institutional repository that provides access to Queen's research output. Every effort has been made to ensure that content in the Research Portal does not infringe any person's rights, or applicable UK laws. If you discover content in the Research Portal that you believe breaches copyright or violates any law, please contact openaccess@qub.ac.uk. 
“Role-Related Stress and Perceptions of the Keyworker Role among Professionals Supporting Adults with Intellectual Disabilities"

\begin{abstract}
Purpose Individuals with intellectual disabilities who are users of day and residential services will often be assigned at least one 'keyworker', a staff member who is expressly responsive to their needs and responsible for coordinating services with them. Keyworkers are often given their role because it is a norm in their organisation. However, given the emotionally intensive workload involved in coordinating care for a single individual, little attention is given to the potential stress burden of being a keyworker.
\end{abstract}

Design A cross-sectional survey study was conducted of professionals' perceptions of the keyworker role and of levels of workplace wellbeing. We first examine differences between keyworkers and their colleagues along measures of role perception and wellbeing. We then present a new measure of Keyworkers' Duties and Boundaries (Key-DAB) capturing perceptions of the keyworker role by keyworkers and other staff. The measure was administered to a sample of staff ( $N=69$ ) from an Irish provider of services for adults with intellectual disabilities. Alongside the new scale, we administered established measures of workplace wellbeing and Locus of Control (LoC) to examine construct validity and assess if perception of keyworking could be related to stress.

Findings Some differences were detected between keyworkers and non-keyworkers: keyworkers had more internally-oriented LoC and experienced lower Work Pressure than non-keyworking colleagues. The Key-DAB measure possessed favourable psychometric properties, including high internal reliability. External validity was also shown as keyworkers' scale scores were related to Locus of Control and to role demands. Results suggested: 1) that keyworkers who are clear about what is expected of the keyworker are more satisfied with their role and perceive keyworking as beneficial to them; 2) that Role Ambiguity and Role Conflict can undo these potential benefits and render the keyworker's role a potentially hazardous one.

Value We recommend that employers provide clear guidelines and explicit training to keyworkers and suggest that our measures may be effective tools for ongoing assessment of keyworkers' role clarity. 


\section{Introduction}

For an organisation providing services to adults with intellectual disabilities, the wellbeing of frontline staff is a vital component of service quality. There has been a steady move towards both simultaneously integrating and personalising social care services, including services for people with intellectual disabilities (Lymbery, 2012; Yeandle, Kroger and Cass, 2012). An important dimension of this movement has been the creation of roles which facilitate service users having a central coordinator and identified person through whom the service landscape can be navigated (NHS Scotland, 2009).

One such role is that of the keyworker ${ }^{1}$ : a member of the staff team assigned to a particular service user and charged with becoming especially familiar with that person, their case details and their needs, and with liaising between the important individuals in the person's life (Whitehouse, Chamberlain and Tunna, 2000; Greco and Sloper, 2004; Hull and Turton, 2014). Keyworking roles have the potential to give staff a sense of empowerment and value within the service (Prestler, 1998, Tait and Dejnega, 2001; Greco, Sloper, Webb and Beecham, 2006), to facilitate development of new skills (Willner et al., 2013; Parr, 2016) and to create enhanced emotional connections with the 'key person' or 'key service user' (Fornells-Ambrojo et al., 2015; Griffiths and Smith, 2015). However, keyworkers could be vulnerable to a 'creep' effect, whereby their role expands in proportion to the service user's needs and to the level of expectation of the organisation and among colleagues. From an organisational perspective, the possible impact of this on staff members' stress, wellbeing and identity within that organisation should be of acute concern.

Literature searches revealed usage of the keyworker role in social care settings in diverse national and systemic contexts, from the United Kingdom (Whitehouse, Chamberlain and Tunna, 2000), Ireland (McConkey, Keogh, Bunting and Iriarte, 2018) and several Nordic countries (Hansson et al., 2008), to Australia (Kennair et al., 2011) and India (Murthy, 1998). It is difficult to estimate how prevalent the role is across intellectual disability services and how this compares to other areas of service delivery. In a recent study, with a mixed sample of 119 people using one of 12 services for intellectual disability and six mental health services in Ireland, keyworker ratings of life satisfaction were available for $70 \%$, with those with intellectual disabilities slightly more likely to have a keyworker rating (McConkey et al., 2018). This suggest very widespread usage in this context, though it must be noted that all 18 services were run by the same provider, and that some of those

\footnotetext{
1 'Keyworker' is used throughout this manuscript in preference to 'key worker'; we describe the person to whom the keyworker is assigned as 'the service user' or 'key person'. In line with the conventions of the participating organisation, the term 'client' or 'key client' was used throughout the questionnaire described.
} 
without keyworker ratings may have been due to non-response. On the other hand, the only systematic investigation of keyworker and care co-ordination prevalence which we found surveyed UK providers of services for children with disabilities (Greco and Sloper, 2004). In this sample only $22 \%$ of services had care co-ordinators and only $18 \%$ used the term 'key worker'. However, the study exemplifies how child and adult services represent distinct contexts, as keyworkers in this study were characterised as service liaisons for the family, rather than for the individual service user, reflecting the different living arrangements for children and adults.

The emotional dimension of keyworking has been explored in a small number of studies, with keyworker-key person interactions found to involve mutual, cooperative and empathetic 'attuning' to one another (Griffiths and Smith, 2015). In the context of mental health services, keyworkers have been found to pay an emotional toll where their assigned person experiences more severe forms of personality disorder and psychosis (Fornells-Ambrojo et al., 2015), while in intellectual disability settings, Archibald has highlighted the potential risks to keyworkers' wellbeing where the boundaries of the keyworking relationships are poorly explained to, misunderstood by or ignored by the key person (2001).

Relatedly, there is no settled definition of a keyworker's role: each keyworking relationship will be defined in part by the overall organisational context in which the relationship is formed, by the expectations both parties have of the role (Hull and Turton, 2014; Bland, 1997; McGrath and Pistrang, 2007). The literature sometimes casts the keyworker a 'case manager' or 'care coordinator' (Hull and Turton, 2014; Greco and Sloper, 2004). For keyworkers with adults, duties can include the drawing up and updating of individual care plans, conducting regular reviews of the individual's progress and service quality, maintaining working records pertaining to the individual and ensuring necessary support from social workers upon discharge or transition within the service (Residential Care Association, 1976 in Bland, 1997). Others have described instances where keyworkers are expected to exert authority, to set limits and boundaries for service users in order to maintain an overall quality of service for all service users (McGrath and Pistrang, 2007). However, in the context of keyworkers running therapeutic groups, Willner and colleagues note apprehension among some keyworkers around having to exert authority and keep order (2013). One paper by Yacoub and Hall (2008) explored the role of keyworkers in male key persons' sexual development. In the main, interviewees reflected on the keyworker as having a positive and supportive role in providing information and facilitating access to sexual health services. However, issues of professional boundaries also arose here with one interviewee expressing a preference that future keyworkers be prepared to accompany him to strip clubs. 
This wide range of potential responsibilities demonstrate how the particular nexus of expectations and values held by the key person, the keyworker's colleagues and the keyworker themselves could create highly localised definitions of the keyworking role and, consequently, disparities within organisation and teams as to the workload attached to keyworking. Additionally, the keyworker duties identified in the above literature could overlap with those of a manager, social worker, or 'ordinary' member of a staff team (Greco and Sloper, 2004). Keyworkers interviewed by Greco and colleagues (2006) often contradicted their colleagues in their accounts of which duties fell to them, and which fell to the staff team. Interviewees also differed on the level of contact with families and other professionals which they believed to be appropriate. Ambiguity was particularly pronounced among those who had not received specific keyworking training and for whom guidelines around keyworking duties and the boundaries of this role were less clear.

The potential for ambiguity among keyworkers is concerning when we consider evidence around workplace stress in the social care domain, where scores along measures of role ambiguity and role conflict have each been associated with elevated stress levels (Hatton et al., 1999). Hatton identifies issues pertaining to the organisational role among eight categories of factors impinging on stress. Furthermore, role definition and role-specific training are associated with further factors such as organisational structure and climate and scope for career development and with mediating predictors of distress such as job strain (Hatton et al., 1999; Haynes et al., 1999). Rose's study of demands and supports for residential staff working with intellectual disabilities suggests that while the keyworking role did not appear to contribute to the burden of job demands, that there was variation in managerial support for the role and that lower managerial support was associated with lower cohesion and staff morale (1999).

Personality is an important dimension of how people develop differing perceptions of their organisational role. It has been noted that the personality traits of both the keyworker and key person will shape the nature of the role and relationship (Hull and Turton, 2014; Bland, 1997; McGrath and Pistrang, 2007). In organisational literature, 'Locus of Control' is one facet of personality which has been implicated both in the type of workloads people undertake and in their levels of job satisfaction (Parkes, 1991). People with more externally oriented Locus of Control attribute events to factors in the environment while internally orientation places responsibility for events on one's own actions or traits (Rotter, 1966). Internally-oriented individuals are less likely to remain in dissatisfying work conditions, and are therefore likely to achieve greater job satisfaction, either by seeking to improve their existing conditions, or by moving elsewhere (Spector, 1982 in Judge and Bono, 2001). Internal orientation can also help individuals use their discretion to manage 
their workload demands (Parkes, 1991). This variation in personality differences could underlie differences in how a person perceives expectations of them in their job role, with more internallyoriented keyworkers ascribing more responsibility to themselves.

\section{Research Questions}

While significant attention in the literature has been devoted to the importance of workplace stress and morale among those who provide frontline services, any additional stress burden from the keyworker role, or ambiguity around its boundaries, remains unexplored. If such additional burdens existed, organisations would have to calculate whether the benefit to their service of using the keyworker model is commensurate with the administrative cost of clearly codifying how the role is defined and the potential costs to staff morale and, in turn, service users. Conversely, if keyworkers are particularly healthy and enjoy additional role satisfaction, the onus on the organisation is to extend keyworking to as many staff members as possible. In any event, it is not tenable to maintain the assumption one is engaged in best practice without evaluating the consequences of the practice. This paper begins to redress this by addressing the following research question:

RQ1: Do keyworkers differ from their colleagues in their levels of workplace wellbeing and perceptions of their professional role (and to what extent are any differences attributable to other group differences such as age and level of experience)?

We also exploit the wide array of duties which could be interpreted as germane to the keyworker role in order to identify care staff along a continuum of degrees of responsibility which they ascribe to the keyworker. In addition to assessing the psychometric properties (internal reliability and construct validity) of this and other indicators of perceptions of and experiences in the keyworking role, we examine which factors influence an individual's scores on those measures and potential relationships between this and key predictors of organisational stress. This is encapsulated in the following research questions

RQ2: Which role-related cognitions, individual attributes and organisational conditions predict greater role satisfaction and lower role stress for keyworkers?

RQ3: Are keyworkers' perceptions of keyworking associated with with individual attributes (including Locus of Control) and with workplace wellbeing?

Rationale for a pilot survey The literature reveals a lack either of evidence suggesting what differences we might expect from the research questions above, or of validated tools which could be used to address these questions. 
Hence, a pilot survey with a combination of established indicators of work stress and new proposed measures concerning keyworkers' role perception was considered an appropriate next step. We accept from the outset that in the context of a small-scale cross-sectional pilot study, there are limits to what we can learn about the causal relationships between keyworking and workers' wellbeing. However, the literature reveals potential for variations in individuals' understanding of the keyworking role, pointing to a need for tools and systematic strategies with which organisations and researchers can ascertain how individual staff members perceive the role of the keyworker.

\section{Methods}

Procedure

Data were collected through the administration of a multi-variable questionnaire survey. The questionnaire included newly-developed measures being piloted for the first time, aimed at assessing perceptions of the role of keyworker and experiences in the role, including the level of responsibility ascribed by participants to keyworkers for service planning and delivery for their key person. The construction of these measures was informed by published literature introduced in the previous section and ensuing sections around keyworking demands, supports and potential role ambiguities (c.f. Greco et al., 2006; Bland, 1997), by keyworking guidelines available to employees from the host organisation, and by a focus group discussion.

The host organisation was a large service provider for adults with intellectual disabilities in the south of Ireland. Ethical approval for the study was obtained from the Trinity College School of Psychology Research Ethics Committee. Consistent with APA's guidelines for research with human participants, participants were assured of the anonymity of their participation, the confidentiality of their data, and their ability to withdraw from participation at any time without penalty. Completion of the questionnaire was taken as consent to participate.

The focus group consisted of five staff working in a residential unit of the service provider. All five were current or former keyworkers and worked together as a team. Following from the theme identified by Greco and colleagues (2006) of keyworkers' ambiguity around their duties and around the boundaries of the keyworking role, the title of the discussion was "the boundaries of the keyworker's responsibilities". The aim was to elicit discussion of keyworkers' experience in the role and suggest tasks which could be differently interpreted by staff members as a keyworker's responsibility, or as a managerial or collective staff responsibility. The itinerary of duties included on the final questionnaire is described in detail in the results section. 


\section{Survey Sample}

The questionnaire was made available online via a Survey Gizmo link. This link was distributed via a human resources list with the contact details of 154 of the host organisation's employees. Thirty participants completed and submitted the online questionnaire.

Paper copies of the questionnaire were also made available at training courses and through direct delivery to residential units and four day-service centres. Paper copies were sealed and returned to the primary researcher via unit managers in order to maintain confidentiality. This approach yielded a further 39 responses, rendering a total sample of 69 participants.

Of the 69 participating staff members, 54 were women (78\%), 14 were men (20\%) and one participant did not state their gender. The modal age bracket was $26-35$, and $65.3 \%$ of participants were aged between 26 and 45 . Thirty-six respondents (52\%) worked in residential units, $27(41 \%)$ in day/training services, and the remaining $4(7 \%)$ worked in supported employment centres, supported independent living services, and administration. Forty-five (65\%) were on full-time contracts, 16 (23\%) part-time, 7 (10\%) were relief staff and one did not specify. Thirty-nine respondents (57\%) were currently assigned as keyworkers, 11 (16\%) had been keyworkers in the past but were not currently, and $19(28 \%)$ had never been keyworkers.

\section{Measures}

\section{Keyworkers' Duties and Boundaries (Key-DAB)}

The Keyworker Duties and Boundaries (Key-DAB) inventory was created in the course of the study to capture the varied perceptions of the keyworker role. It consisted of 22 multiple-choice items, each describing a possible duty of the keyworker. Participants were asked to select the option which best described who within the staff team was responsible for each duty. Response options, response patterns and the content of the measure as a whole are described in greater detail in the results section.

\section{Experiences with the Keyworking Role}

An additional array of items were presented concerning keyworkers' direct experience of the role (31 items) and non-keyworkers' indirect experiences with the keyworking role (22 items). These were not organised into any putative scales per se: rather, these constituted an overview of areas where variance may exist in perception and experience of the role. The content of these items was informed primarily by published literature, in particular the role demands and role support scheme of Rose (1999), and interview schedules of Greco and colleagues (2006). Additional items were added on the basis of discussions with focus group participants around the extent of their 
keyworking experience, (e.g. the number of key persons assigned to them by the organisation to date) and their perceptions of the training, resources and supports available to specifically help with the fulfilment of their role as keyworker.

\section{Occupational Wellbeing}

In addition to the newly developed measures, respondents were presented with psychometrically sound and established measures. Scales capturing Job Autonomy ${ }^{2}(\alpha=0.83-0.89)$, Perceived Influence over Work Decisions $\left(\alpha=0.82-0.86^{3}\right)$, Role Clarity $(\alpha=0.83-0.85)$, Role Conflict $(\alpha=0.78$ 0.90 ), Peer Support ( $\alpha=0.90-0.92$ ) and Supervisor Support ( $\alpha=0.90-0.93$ ) were designed for a study of National Health Service employees in the United Kingdom (West et al., 1996): validation procedures and psychometric properties were later reported by Haynes and colleagues (1999). Additionally, a 5-item scale was included to measure Work Pressure from Rose's survey of demands on residential staff working with adults with intellectual disabilities (1999) with that author's permission. Rose reported Cronbach's $\alpha$ of 0.69 and found this scale to be the strongest of four demand-related predictors of both anxiety and depression.

Additionally, a 6 -item measure of Satisfaction with Work $(\alpha=0.59)$ was included, adapted from previous research with residential carers of adults with intellectual disabilities (Hatton, 1999). Participants rated on a 4-point Likert scale their satisfaction with six domains of work satisfaction, satisfaction with relationship with colleagues, with relationship with management, with service user relationships, with scope to help service user achieve personal goals, with pay and conditions and ability to communicate with management.

\section{Personality, Demographics and Experience in Social Care}

Respondents were also asked to give background details including their gender, approximate age, the ability levels of the service users with whom they worked primarily and the approximate ratio of staff to service users where they worked.

The survey also included Rotter's 13-item internality/ externality measure of Locus of Control (LoC; 1966). Higher scores represent more external orientation of LoC.

\footnotetext{
2 Job Autonomy is acknowledged as an adaptation of the scale for the general workforce by Jackson, Wall, Martin and Davids (1993).

${ }^{3}$ Cronbach's $\alpha$ scores for general wellbeing reflect the range reported across seven health service occupations by Haynes et al. (1999), including nurses, doctors and Professionals Aligned to Medicine (PAMs)
} 
Analysis

In order to address Research Question 1, we assessed any differences in wellbeing outcomes were associated with keyworking in three steps. First, we compared the characteristics of the three keyworking groups (current, former and never). The purpose of this comparison was to identify any underlying group differences which might account for differences in wellbeing scores. Demographic variables and dimensions of job context were compared using contingency tables and accompanying Fisher's Exact tests where those variables were categorical (e.g. gender, age group) and using ANOVA where they were interval (e.g. time in organisation). By way of post-hoc tests, two pooled comparisons were carried out using t-test, one grouping anyone with keyworker experience (i.e. current and never) and the other grouping all those not currently keyworking (i.e. former and never). This was so that any differences would not be incorrectly ascribed to current work conditions if they reflected historical experience within the organisation. In the next step, the same structure of comparison of means was carried out for indicators of wellbeing. In the third step, for any wellbeing indicators which differed across keyworking categories, Ordinary Least Squares multiple regression models were specified adjusting for those differences in profile between the three groups identified in step one. No prior prediction was made as to the direction and nature of these associations, and both linear and non-linear relationships were of interest. Thus, despite the limited sample size, regression was considered the most efficient approach to capturing these effects.

We then analysed perceptions of the keyworking role, as measured on the newly developed Key$D A B$ scale and other items pertaining to keyworking experiences in order to assess Research Questions 2 and 3. The scale-score reliability of Key-DAB was tested using Cronbach's Alpha scores. Predictive validity was examined first through group comparisons of residential-based staff, and day and training services staff, with the expectation that day staff would ascribe more responsibility to the keyworker given the larger staff and service user groups attending day services and, second, by testing whether ascribing more responsibility to keyworkers predicted higher scores on LoC, with the expectation that this association would be found among keyworkers but not among nonkeyworkers. This was tested in a simple linear regression model. Finally, the predictive utility of newly developed measures was assessed through exploration of how keyworkers' circumstances and perceptions affected their work stress and work satisfaction.

Given the exploratory nature of this analysis, results are interpreted as giving an indication of where future studies should focus when assessing connections between keyworking, staff wellbeing and organisational cohesion. 


\section{Results}

Comparing keyworkers and non-keyworkers

Comparisons of characteristics between persons currently keyworking, former keyworkers and nonkeyworkers are presented in Table 1. Most of the differences were small and not statistically significant. For example, male staff members were similarly likely to have been keyworkers as their female counterparts; and former keyworkers were older than the other groups, though ANOVA suggests these differences were greater than that which would be expected by random chance.

However, some significant differences were found: non-keyworkers reported working with service users with greater needs; keyworkers were more experienced than non-keyworking members, as revealed by ANOVA comparisons of time served in the organisation, in the participant's current job and in the field of social care; and keyworkers were more internally oriented on Rotter's LoC scale than non-keyworkers, suggesting that the role may be associated with distinct personality traits.

\section{(Insert Table 2 around here)}

The descriptive distribution of wellbeing outcomes is summarised in Table 2. Participants in the survey expressed a high degree of overall satisfaction with their work, with mean responses at 19 on a scale with a possible range of 6-24. No differences in overall work satisfaction were found between keyworkers and other staff.

The only two wellbeing indicators where group differences were statistically significant were Work Pressure and Job Autonomy and Control. Current keyworkers were found to have lower overall perceived Job Autonomy than those not currently keyworking. Given that there were no characteristics along which current keyworkers differed from those not currently keyworking, no adjusted models were specified to test for missing third variable influence.

Participants who had never been keyworkers reported higher mean scores on the Work Pressure scale than those with keyworking experience. Conversely, current keyworkers reported lower Job Autonomy and Control than persons with no current keyworking duties. Given that these groups differed on three baseline characteristics, time served in organisation; external LoC and service users' level of needs, linear regression models were specified to investigate whether this difference 
might be accounted for through other sources of variance ${ }^{4}$. Keyworker experience first entered as a solo predictor and then entered alongside three covariates. Whereas the keyworking experience coefficient in the unadjusted model is -1.32 (SE,0.64), this coefficient is reduced to $-0.55(\mathrm{SE}, 0.77)$ in the model adjusting for covariates. This suggests that the greater perceived service user level of need and higher external LoC of respondents who have never been keyworkers account for higher perceived Work Pressure among this group.

(Insert Table 3 around here)

Key Duties and Boundaries (Key-DAB Scale)

\section{Item Generation}

The literature review generated a substantial list of components of their key person's service requirements for which keyworkers were found to have to take some personal responsibility or felt there was some expectation of responsibility from others. Pearse and Smith (2000) identify facilitating access to services as part of the keyworker role. This is captured in items around scheduling on behalf of the service user (e.g. [Who is responsible for] "Making medical appointments for the key person)". Greco and colleagues (2004) emphasises the care co-ordinating element of keyworking and their responsibility for maintaining and implementing a personalised care plan for the person. This is captured in items such as [Who is responsible for] "Maintaining contact between staff in the various services the client accesses [training, residential, job-coaching, etc.]".

Focus group discussions served to be more generative than exclusionary: respondents agreed that in most cases, the duties described in the literature resonated with the experience of keyworking within their team. Further items were added on the basis of this discussion and on the basis of written guidance issued to the organisation on the keyworker role, e.g. detailed personal care ([Who is responsible for] "Ensuring that the key person is observing proper hygiene").

\section{Response options}

Bland's 1997 critique of the keyworking role highlighted two ambiguities around keyworking boundaries: 1) the boundary between keyworker and management; and 2) the boundary between keyworker and "ordinary" staff colleagues. Focus group participants agreed that these were boundaries which could vary from one keyworking relationship to another: some keyworkers felt at least partial responsibility for aspects of their key person's care, while others saw the same task as equally borne by all staff members. Hence, respondents were asked to choose which of five options

\footnotetext{
${ }^{4}$ Given that only one wellbeing outcome variable showed a significant group difference between groups with different underlying baseline characteristics, these results are presented here in text and not in tables
} 
best described whose responsibility each duty was: "Keyworker"; "Keyworker and Staff Team Together"; "All Staff Members"; "Keyworker and Manager Together"; and "Manager".

\section{(Insert Figure 1)}

\section{Scoring Key-DAB}

For the purpose of aggregation, we experimented with three coding approaches to Key-DAB items responses: two binary codings and one Likert-style coding. In the first binary coding, a response of "Keyworker" was coded as 1 and any other response was coded as zero. Therefore, scores from 0-22 reflected the number of duties for which respondents saw a keyworker as the sole or main person responsible. In a second binary coding, a response of "Keyworker", "Keyworker and Staff Team Together", or "Keyworker and Manager Together" were coded as 1, and "All Staff Members" and "Manager" as 0 . Therefore scores from 0-22 reflected the number of duties for which respondents saw keyworkers as having any responsibility. In a third Likert-style coding, "Keyworker" was coded as 2 , keyworker plus others as 1 and others as 0 . Therefore scores could range from 0-44 and would reflect more latent perceptions of the role's boundaries.

\section{Key-DAB Responses}

A total of 57 survey respondents (33 current keyworkers, 17 non-keyworkers and seven former keyworkers) completed the newly devised 'Key Duties and Boundaries (Key-DAB)' measure. The nonresponses were all from participants who completed the paper version of the survey. This may have been due to the design of the paper version, where the Key-DAB item was printed on the back page of the questionnaire booklet.

Participants gave a variety of responses when asked to select an actor or group responsible for each of 22 tasks listed. The most popular response among respondents for 13 of the 22 task items was "Keyworker and staff team together", though this item was never selected by more than 26 times for a single task (i.e. $46 \%$ of respondents, as it was for the item "Finding out the service user's personal outcomes, goals and aspirations"). "Management" was consistently the least popular option: in the full array of 22 responses from 57 participants, "Management" was selected only 45 times, a maximum of eight times for one task item, "Contacting other healthcare professionals on behalf of the service user". The solo "Keyworker" option was selected 204 times, most frequently for the task item "Filling out paperwork specific to the service user", and least frequently for the item "Ensuring the service user is observing proper hygiene", which only one respondent selected as the sole responsibility of the keyworker. 
Overall scores were also highly variable: scores using the binary coding varied from zero items selected as keyworker responsibility to all 22 items. Mean scores using each of the three coding approaches outlined above are provided in Table 3, along with Cronbach's Alpha scores. On average, participants identified 3.5 of the 22 tasks as keyworkers' sole responsibility (SD $=3.7)$ and 10.4 (SD = 6.0) as the responsibility of the keyworker plus another person. High internal reliability was shown for Key-DAB, with two coding structures approaching the 0.90 standard for Cronbach's Alpha (Table 3). These were the Likert-style coding (0.89) and the binary coding where selecting any option involving the keyworker was coded as 1 (0.91).

There was evidence, via independent sample t-tests, that this scale differentiated between groups with distinct experiences of the keyworker role, with residential and community-based staff registering lower mean Key-DAB scores than staff working at daytime training units $(t[51]=4.29, p<$ $0.05)$.

There was a positive relationship, among keyworkers, between ascribing more duties to keyworkers and having more internally-oriented LoC. Comparing linear models where Key-DAB is regressed on LoC, we see that one point towards the External end of the Rotter scale is associated with a lower Key-DAB-Likert score of 0.2 standard deviations. Among non-keyworkers, the association is much weaker and not significant at the $95 \%$ confidence level. In effect, keyworkers responding to Key-DAB are identifying tasks for which they themselves are responsible. Therefore, it is logical that more internally-oriented keyworkers would nominate themselves for more duties and that among nonkeyworkers, for whom the exercise is a more abstract one as the tasks relate to someone else's workload, the relationship with LoC should be weaker.

\section{(Insert Figure 2 around here)}

Furthermore, examining the scatterplots for the Likert-coded Key-DAB scores among keyworkers, it is apparent that the relationship with LoC is non-linear. A quadratic relationship between LoC and Key-DAB was a better overall fit to the data: people with the most internally oriented LoC nominated the keyworker for more duties than those with most externally oriented LoC, but for fewer duties than those in the middle of the LoC distribution.

Note also that the other codings of Key-DAB did not detect these differences as clearly, suggesting that the Likert coding is most sensitive to the individual differences which relate to the underlying construct of how the role is perceived. 
The predictive validity and importance of the Key-DAB constructed was examined by testing whether Key-DAB scores predicted scores on established indicators of workplace wellbeing. These were perceived Job Autonomy, Work Pressure, Role Clarity, Role Conflict, Supervisor Support and Peer Support (Hatton et al., 1999; Haynes et al., 1999).

In all cases, a curvilinear distribution was a better fit for the bivariate relationship between Key-DAB and wellbeing. Job Autonomy declines on average as the number of duties identified as involving the keyworker increases from 1 up to 11, but then increases thereafter. Conversely, perceived Work Pressure declines up to 15 duties identified, but then increases thereafter. In the case of Job Autonomy, this association was only clearly visible using the "Any Involvement" coding of keyworkers' duties, whereas for Work Pressure, the effect was also significant using the Likert-style coding. These were the only indices of workplace wellbeing predicted to the level of statistical significance by Key-DAB scores. In both cases, associations were robust to adjustment for keyworking experience and LoC.

As well as using the full scale distribution, additional exploratory analysis was conducted using separate tallies of each of the five response options on the Key-DAB. This revealed further betweengroup differences. Former keyworkers identified a task as the responsibility of keyworker and management more often than others, while those with no keyworking experience identified the fewest of these.

When the tallies are combined such that categories reflect the number of keyworker, partkeyworker or others' duties, those with no keyworking experience identify fewer items either as keyworker or part-keyworker duties. Current keyworkers identified the greatest number of tasks as part-keyworker duties on average.

\section{Experiences of the Keyworker Role}

Of the 50 keyworkers surveyed, 47 answered questions about the focus given to the keyworking role within the organisation and within their team (Table 4). Forty-one reported having had discussions with team colleagues about the keyworker role, with six not reporting having had any team-level discussion regarding role parameters. Of these, 19 found the discussions among staff "Very beneficial": 20 found them "Somewhat beneficial" and 2 found them "Not greatly beneficial". Finding these discussions beneficial was associated with greater Role Clarity and perceived Influence Over Decisions. Twelve people reported having 'reasonably regular' or 'very regular' discussion with their manager about their keyworking role, while 34 people found discussing their role with their manager somewhat or very beneficial. 
Keyworkers were asked to compare their relationships with key service users to other relationships in their unit setting. Of 23 keyworkers described their relationship as more positive than their relationship with other service users, which was associated with higher mean Peer Support scores. Of 42 who responded, 25 reported having "Much more positive" or "Somewhat more positive" relationships with their key service user than other staff members, which was associated with higher levels of Work Pressure, though at a level marginally below that of statistical significance.

\section{Discussion}

Personalising any service can be a step towards improving the experience of both the service provider and the recipient. However, if this comes at a cost to professionals' autonomy and boundaries, an organisation must proceed with caution. Assigning a keyworker to an adult services user, from the wider pool of social care staff with whom pre-existing knowledge and trust exists, is an established practice and one viewed as having great potential for success (NHS Scotland, 2009). From the perspective of adult with an intellectual disabilities and their families, having a central point of contact who has as a central concern that individual's aspirations, goals and needs brings them closer to a personalised mode of support (Yacoub and Hall, 2008; NHS Scotland, 2009). For the keyworker, the role can add a sense of meaning, agency and connectedness to their overall organisational role (Pearse and Smith, 2000).

However, the current paper demonstrates that even within a single organisation, there can be significant variability in how the keyworking role is understood and the level of responsibility and duty which staff members attach to the role. Furthermore, there is tentative evidence that these role perceptions may be related to indicators of organisational wellbeing and stress, albeit in a complex fashion. Non-linear relationships were found between the amount of responsibility people attached to their keyworker role and their levels of perceived Work Pressure and perceived Job Autonomy. These relationships are complex in that both are non-linear. Furthermore, while one suggests that Work Pressure is minimised where keyworkers identify medium levels of responsibility, Job Autonomy is also lowest in this range. Given that Job Autonomy inflects upwards at an earlier point, the tentative signal from the data is the medium to high levels of keyworker involvement yield the best combination of Work Pressure and Job Autonomy.

The main contribution of this analysis is the newly devised inventory of 'Key Duties and Boundaries (Key-DAB)'. To our knowledge, this the first measure designed to capture keyworker role perceptions. Responses to this inventory can be coded and computed as a scale: respondents with higher scores ascribe more responsibilities to keyworkers and understanding this role as more 
central to the key person's care. In our preferred Likert-style coding, a response indicating "Keyworker" as solely responsible for the task is coded as 2 points on the scale, "Keyworker plus manager/colleagues" is coded as 1 and "Management" or "All Staff Members" are coded as 0. This scale demonstrated showed strong reliability and moderate predictive validity. However, while the sample size of 69 was comparable to other studies of social care workers and of keyworkers (e.g. Dempsey and Arthur, 1998, Greco et al., 2006), a major limitation of the scale as devised in this study is that participants were drawn from a single organisation. Therefore, the norms of the organisation whose staff contributed to its design and in which it was trialled will have influenced the range of observed responses. Thus, further testing is needed to establish how appropriate its use would be in other social care settings.

Further to this, even within the service provider in this study, the keyworker role meant different things depending on the setting in which it was applied. Staff in day service were more likely to have been keyworkers and identified more duties as keyworker duties. Day services keyworkers work within larger teams with a large number of service users than residential services (Rose, 1999). Also, keyworkers and key persons work in tandem to a consistent daily routine in contrast to the residential setting, where a subset of the team will usually work to a shift pattern. Thus, keyworking can more easily be used as a means to delegate responsibilities in the day service setting. Sensitivity to these contrasting contexts may be important to developing training, resources and team practice guidelines to support keyworkers and to inform their key person and their family. In the current study, the majority of respondent found conversations at unit level around the keyworker role beneficial, though a significant minority did not report having had any such conversations. A limitation of the current study is that looking at team-level variations, or variations between family and staff perceptions of the keyworker role, were beyond the scope of this study. With further development, Key-DAB could be a useful inventory both for researchers and for organisations wishing to monitor both individuals' understanding of the role and the level of agreement and common understanding among team members of what responsibilities fall to a keyworker. Furthermore, testing within a larger and more representative sample from across services would allow for more robust between-group comparisons, including between keyworkers and nonkeyworkers, to further explore the mechanisms and context through which the keyworking role might influence wellbeing.

The Key-DAB construct is shown to have a relationship with Locus of Control (LoC). Externally oriented LoC has previously been shown to predict lower workplace stress and to moderate responses to workplace stressors (Spector, 1988; Parkway et al., 1988). However, adjusting for LoC 
did not account for the relationship between perceptions of responsibilities and workplace stress. Furthermore, a linear association between internal LoC orientation and more perceived keyworker duties was not supported by the data. Rather, respondents ascribed more duties to the keyworker if they were very internally or very externally oriented on the LoC scale. This suggests that more internally oriented keyworkers may feel empowered, not only to take on tasks pertaining to their key service user, but also to delegate, to enlist support and to share tasks with colleagues. It may be that roles which lack settled definition might have the potential to affect staff with different personalities to different degrees.

Another aim of this study was to detect what if any differences existed between keyworking and non-keyworking groups along indicators of wellbeing and other relevant characteristics. Given the exploratory nature of these analyses, we have focused on statistically significant differences in the results section. Where differences are observed they usually do not meet the level of statistical significance. In the case of Work Pressure, group differences appear to be attributable to other differences in the profile and make-up of keyworkers versus non-keyworkers. These group differences are interesting in and of themselves, namely the more external orientation on Locus of Control of people who have never been keyworkers and the perception of higher demand from service users among that group. This suggests that there may be some selectivity in use of the keyworker role both between units with different levels of service user needs and between individual staff members on the basis of personality. Further research is needed to clarify whether these patterns can be generalised, especially given that these differences were not predicted at the outset of this study in specific hypotheses but identified in the course of exploring the data. If similar differences were found in future studies, organisations could account for these differences through a personalised and bespoke keyworking training programme focused on professionals' individual attributes and strengths.

Overall the main signal from these comparisons is that there is little difference in wellbeing between keyworkers and their colleagues. Therefore, the tentative evidence is that risks to wellbeing should not be seen as a risk factor attached to keyworking by staff or by service planners, provided the aforementioned issues around role clarity and boundaries are taken into account. The one difference detected was lower perceived Job Autonomy and Control among current keyworkers. Given that this has been shown to predict lower overall wellbeing among community support workers (Rose, 1999; Hatton, 1999), organisations might do well to consider mechanisms through which keyworkers can have flexibility to plan their work and manage demand on their work time generated through keyworking duties. 
A key aim for future research could be to enhance the voice of service users in the discussion of how best to configure keyworkers' roles. Given the findings of Archibald (2001) and Yacoub and Hall (2008) which point towards areas of potential discordance between keyworkers' and key person's perceptions of the key relationship, the Key-DAB itinerary could be used as a framework for helping service users and their families to develop an agreed understanding of what areas of the person's life their keyworker will be involved in.

Another important contribution of the current study is the importance of training and discussion around keyworking duties. Better-trained keyworkers report lower levels of perceived Work Pressure, while regular discussion of the keyworker role was associated with greater perceived support from colleagues and supervisors. Organisations employing the keyworker model could help to improve staff wellbeing by ensuring keyworkers are trained and that a culture of open discussion of the role is encouraged. Keyworker-specific training could encompass both good practice for relating to service users, families and colleagues as well as giving staff the knowledge and confidence required to inform important decisions around care planning (c.f. Whitehouse et al., 2000).

Thus, it is our conclusion that without adequate support and clearly defined boundaries around the keyworking role, its potential for enhancing workplace wellbeing and, in turn, for improving the support for the service users, may not be fully realised. 


\section{References}

Archibald, C. (2001), "Resident sexual expression and the key worker relationship: An unspoken stress in residential care work", Practise: Social Work in Action, Vol. 13 No. 1, pp. 5-12.

Bland, R.E. (1997), “Keyworkers re-examined: Good practice, quality of care and empowerment in residential care of older people", British Journal of Social Work, Vol. 24 No. 7, pp. 585-603.

Dempsey, I. and Arthur, M. (1998), “Characteristics and professional development needs of staff working in employment services for people with a disability", Journal of Intellectual and Developmental Disability, Vol. 23, No. 4, pp. 333-342.

Fornells-Ambrojo, M., Pocock, P., Mintah, R., Barker, C., Craig, T. and Lappin, J.M. (2015), “Co-morbid personality disorder in early intervention psychosis clients is associated with greater key worker emotional involvement", Early Intervention in Psychiatry, Nov.

Greco, V. and Sloper, P. (2004), "Care coordination and key worker services for disabled children: results of a UK-wide survey", Child: Care, Health \& Development, Vol. 30, No. 1, pp. 13-20.

Greco, V., Sloper, P., Webb, R. and Beecham, J. (2006), “Key worker services for disabled children: the views of staff", Health and Social Care in the Community, Vol. 14, No. 6, pp. 445-452.

Griffiths, C. and Smith, M. (2015), “Attuning: a communication process between people with severe and profound intellectual disability and their interaction partners", Journal of Applied Research in Intellectual Disabilities, Vol. 29, pp. 124-138.

Hansson, L., Vinding, H.R., Mackeprang, T., Sourander, A., Werdelin, G., Bengtsson-Tops, A., Bjarnason, O., Dybbro, J., Nillsion, L., Sorgaard, K. and Middelboe, T. (2008), “Comparison of key worker and patient assessment of needs in schizophrenia patients living in the community: a Nordic multicentre study", Acta Psychiatrica Scandinavia, Vol. 103, No. 1, pp.45-51. 
Hatton, C. et al. (1999), "Factors associated with staff stress and work satisfaction in services for people with intellectual disability", Journal of Intellectual Disability Research, Vol. 43, No. 4, pp. 253-267.

Haynes, C. E., Wall, T. D., Bolden, R. I., Stride, C. B. and Rick, J. E. (1999), "Measures of perceived work characteristics for health services research: Test of a measurement model and normative data", British Journal of Health Psychology, Vol. 4, pp. 257-275.

Hull, K. \& Turton, P. (2014), “Understanding the concept of a key worker: do focus groups help?", British Journal of Nursing, Vol. 23, No. 15, pp. 854-860.

Jackson, P.R., Wall, T.D., Martin, R. and Davids, K. (1993), “New measures of job control, cognitive demand, and production responsibility", Journal of Applied Psychology, Vol. 78, No. 5, pp. 753-762.

Kennair, N., Mellor, D. and Brann, P. (2011), "Evaluating the outcomes of adolescent day programs in Australian child mental health service", Clinical Child Psychology and Psychiatry, Vol. 16, No. 1, pp. 21-31.

Murthy, R.S. (1998), "The city of Bangalore, India”, Goldberg, D. and Thornicroft, G., Mental Health in Our Future Cities, Psychology Press, East Sussex, UK, pp. 77-98.

Lymbery, M. (2012), "Social work and personalisation", British Journal of Social Work, Vol. 42, No. 2, pp. 783-792.

McConkey, R., Keogh, F., Bunting, B. and García-Iriarte, E. (2018), “Changes in the self-rate wellbeing of people who move from congregated settings to personalized arrangements and group home placements", Journal of Intellectual Disabilities, Vol. 22, No. 1, pp. 49-60.

McGrath, L. and Pistrang, N. (2007), "Policeman or friend? Dilemmas in working with homeless young people in the United Kingdom", Journal of Social Issues, Vol. 63, No. 3, pp. 589-606.

NHS Scotland (2009), Improving Outcomes by Shifting the Balance of Care: Improvement Framework (Report, July 2009) Edinburgh. 
Parkway, F.W., Greenwood, G., Olejnik, S. and Proller, N. (1988), "A study of the relationships among teacher efficacy, locus of control and stress", Journal of Research \& Development in Education, Vol. 21, No.4, pp. 13-22.

Parr, J. (2016), "Learning about adults with ASD and their relatives", Wright, S.D, Autism Spectrum Disorder in Mid and Later Life, Kingsley, London UK, pp. 288-296.

Pearse, J. and Smith, S. (2000), Keyworking: A Resource on Keyworking for all those working with People with Learning Disabilities, Pavilion Publishing, Brighton, UK.

Prestler, B. (1998), “Care coordination for children with special health needs", Orthopaedic Nursing, March/April (Suppl.).

RCA/BASW (1976), "The relationship between field and residential work", Social Work Today, Vol. 7, No. 12 , pp. $346-348$.

Rose, J. (1999), "Stress and residential staff who work with people who have an intellectual disability: a factor analytic study", Journal of Intellectual Disability Research, Vol. 43, No. 4, pp. 268-278.

Rotter, J.B. (1966), “Generalised expectancies for internal vs. external control of reinforcement. Psychological Monographs, Vol. 80, No. 1, pp. 609.

Spector, P.E. (1988), "Development of the Work Locus of Control scale”, Journal of Occupational Psychology, Vol. 61, No. 4, pp. 335-340.

West, M., Borrill, C., Wall, T.D., Hardy, G.E., Shapiro, D., Carter, A.J., Goyla, D.A., and Haynes, C.E. (1996), Mental Health in the Workforce in NHS Trusts: Phase I Final Report. Institute of Work Psychology, Sheffield, UK. 
Whitehouse, R., Chamberlain, P. and Tunna, K. (2000), "Dementia in people with learning disability: a preliminary study into care staff knowledge and attributions", British Journal of Learning Disabilities, Vol. 28, pp. 148-153.

Willner, P., Rose, J., Jahoda, A., Stenfert Kroese, B., Felce, D., MacMahon, P., et al. (2013), “A cluster randomised controlled trial of a manualised cognitive-behavioural anger management intervention delivered by supervised lay therapists to people with intellectual disabilities", Health Technology Assessment, Vol. 17, No. 21.

Yacoub, E. and Hall, I. (2008), "The sexual lives of men with a mild learning disability: a qualitative study", British Journal of Learning Disabilities, Vol. 37, pp. 5-11.

Yeandle, S., Kroger, T. and Cass, B. (2012), "Voice and choice for users and carers? Developments in patterns of care for older people in Australia, England and Finland", Journal of European Social Policy, Vol. 22, No. 4, pp. 432-445. 
Table 1: Demographics and General Job Dimensions: Differences between Keyworkers (KW), Former Keyworkers and Non-Keyworkers 


\begin{tabular}{|c|c|c|c|c|c|c|c|c|}
\hline & & $\begin{array}{l}\text { Current KW } \\
(N=39)\end{array}$ & $\begin{array}{l}\text { Former } K W \\
(\mathbf{N}=\mathbf{1 1})\end{array}$ & $\begin{array}{l}\text { Never KW } \\
(N=19)\end{array}$ & $\begin{array}{l}p \text { (Fisher's } \\
\text { Exact) }\end{array}$ & ANOVA & $\begin{array}{l}t \text {-test } \\
\text { (Current \& } \\
\text { Former } \\
\text { Keyworkers } \\
\text { pooled) }\end{array}$ & $\begin{array}{l}t \text {-test } \\
\text { (Former and } \\
\text { Non- } \\
\text { Keyworkers } \\
\text { pooled) }\end{array}$ \\
\hline $\begin{array}{l}\text { Gender } \\
(\mathrm{N}=68)\end{array}$ & $\begin{array}{c}\text { Female } \\
(54 ; 79.4 \%)\end{array}$ & $30(79.0 \%)$ & $7(63.6 \%)$ & $17(89.5 \%)$ & 0.26 & - & - & - \\
\hline \multirow[t]{2}{*}{$\begin{array}{l}\text { Service Type } \\
(\mathrm{N}=64)^{ \pm}\end{array}$} & $\begin{array}{l}\text { Day Service } \\
(28 ; 43.8 \%)\end{array}$ & $16(41.0 \%)$ & $6(66.7 \%)$ & $6(37.5 \%)$ & \multirow[t]{2}{*}{0.37} & \multirow[t]{2}{*}{-} & \multirow[t]{2}{*}{-} & \multirow[t]{2}{*}{-} \\
\hline & $\begin{array}{c}\text { Residential } \\
(36 ; 56.3 \%)\end{array}$ & $23(59.0 \%)$ & $3(33.3 \%)$ & $10(62.5 \%)$ & & & & \\
\hline \multirow[t]{3}{*}{$\begin{array}{l}\text { Age } \\
(\mathrm{N}=69)\end{array}$} & $\begin{array}{c}21-35 \\
(35 ; 50.7 \%) \\
\end{array}$ & $21(58.9 \%)$ & $3(27.2 \%)$ & $11(57.9 \%)$ & \multirow[t]{3}{*}{0.49} & \multirow[t]{3}{*}{-} & \multirow[t]{3}{*}{-} & \multirow[t]{3}{*}{-} \\
\hline & $\begin{array}{c}36-45 \\
(19 ; 45.4 \%) \\
\end{array}$ & $10(25.6 \%)$ & $5(45.5 \%)$ & $4(21.1 \%)$ & & & & \\
\hline & $\begin{array}{c}46+ \\
(15 ; 21.7 \%)\end{array}$ & $8(20.5 \%)$ & $3(27.2 \%)$ & $4(21.1 \%)$ & & & & \\
\hline $\begin{array}{l}\text { Months since } \\
\text { first employed } \\
\text { in organisation } \\
(\mathrm{N}=69)\end{array}$ & $\begin{array}{c}\text { Range: 6-360 } \\
\text { Mean: } 84.4 \\
\text { SD }=72.0\end{array}$ & $\begin{array}{c}84.3 \\
(\mathrm{SD}=65.2)\end{array}$ & $\begin{array}{c}149.9 \\
(\mathrm{SD}=88.5)\end{array}$ & $\begin{array}{c}44.7 \\
(\mathrm{SD}=42.8)\end{array}$ & - & $\begin{array}{c}\mathrm{F}(2)=9.06 \\
\mathrm{p}<0.01\end{array}$ & $\begin{array}{c}t(66)=-2.90 \\
\mathrm{p}<0.05\end{array}$ & $\begin{array}{c}t(66)<0.1 \\
\mathrm{p}>0.05\end{array}$ \\
\hline $\begin{array}{l}\text { Level of support } \\
\text { needs among } \\
\text { client group } \\
(\mathrm{N}=69)\end{array}$ & $\begin{array}{c}\text { Range: } \\
1 \text { (Lowest need) } \\
-4 \text { (Highest } \\
\text { need); } \text { Mean = } \\
2.5 \\
\text { SD }=0.8 \\
\end{array}$ & $\begin{array}{c}2.5(S D= \\
0.6)\end{array}$ & $2.0(S D=0.5)$ & $2.7(S D=1.1)$ & - & $\begin{array}{c}\mathrm{F}(2)=3.34 \\
\mathrm{p}<0.05\end{array}$ & $\begin{array}{c}t(67)=1.8 \\
\mathrm{p}<0.05\end{array}$ & $\begin{array}{c}t(67)<0.1 \\
p>0.05\end{array}$ \\
\hline
\end{tabular}




\begin{tabular}{|c|c|c|c|c|c|c|c|c|}
\hline $\begin{array}{l}\text { Number of } \\
\text { Service Users } \\
\text { per Staff } \\
\text { Member } \\
(\mathrm{N}=63)^{ \pm}\end{array}$ & $\begin{array}{c}\text { Range: } 1-7 ; \\
\text { Mean = 4.0 } \\
\text { SD = } 1.7\end{array}$ & $\begin{array}{c}3.9(S D= \\
1.3)\end{array}$ & $4.8(S D=1.7)$ & $3.8(S D=2.4)$ & - & $\begin{array}{c}F(2)=1.0 \\
p>0.05\end{array}$ & $\begin{array}{c}t(61)=-0.7 \\
p>0.05\end{array}$ & $\begin{array}{c}t(61)=0.3 \\
p>0.05\end{array}$ \\
\hline $\begin{array}{l}\text { External Locus } \\
\text { of Control } \\
(\mathrm{N}=65)\end{array}$ & $\begin{array}{c}\text { Range: } 2-12 \\
\text { Mean }=5.8 \\
S D=2.1\end{array}$ & $\begin{array}{c}5.6(S D= \\
1.6)\end{array}$ & $4.8(2.0)$ & $6.8(S D=2.6)$ & - & $\begin{array}{c}\mathrm{F}(2)=3.81 \\
\mathrm{p}<0.05\end{array}$ & $\begin{array}{c}t(63)=2.5 \\
\mathrm{p}<0.05\end{array}$ & $\begin{array}{c}t(63)=0.8 \\
p>0.05\end{array}$ \\
\hline
\end{tabular}

\pm Only day and residential staff are included in comparisons as no participants in the 'other staff' category were current Keyworkers 
Table 2: Wellbeing indicators: Differences between Keyworkers, Former Keyworkers and Non-Keyworkers 


\begin{tabular}{|c|c|c|c|c|c|c|c|}
\hline & & $\begin{array}{l}\text { Current KW } \\
(N=39)\end{array}$ & $\begin{array}{l}\text { Former KW } \\
(\mathrm{N}=11)\end{array}$ & $\begin{array}{l}\text { Never } K W \\
(N=19)\end{array}$ & ANOVA & $\begin{array}{l}\text { t-test } \\
\text { (Current \& } \\
\text { Former KW } \\
\text { pooled) }\end{array}$ & $\begin{array}{l}\text { t-test } \\
\text { (Former and } \\
\text { Non-KW } \\
\text { pooled) }\end{array}$ \\
\hline $\begin{array}{l}\text { Work Pressure } \\
(\mathrm{N}=67)\end{array}$ & $\begin{array}{l}\text { Range: } 6-19 \\
\text { Mean }=12.1 \\
S D=2.46\end{array}$ & $\begin{array}{c}11.8 \\
(\mathrm{SD}=2.1)\end{array}$ & $\begin{array}{c}11.5 \\
(\mathrm{SD}=1.4)\end{array}$ & $\begin{array}{c}13.0 \\
(\mathrm{SD}=3.4)\end{array}$ & $\begin{array}{l}F(2)=1.74 \\
p>0.05\end{array}$ & $\begin{array}{l}t(65)=1.8 \\
p<0.05\end{array}$ & $\begin{array}{l}t(65)=1.0 \\
p>0.05\end{array}$ \\
\hline $\begin{array}{l}\text { Job Autonomy } \\
\text { and Control } \\
(N=69)\end{array}$ & $\begin{array}{l}\text { Range: } 10-24 \\
\text { Mean }=17.1 \\
S D=3.9\end{array}$ & $\begin{array}{c}16.3 \\
(\mathrm{SD}=3.31)\end{array}$ & $\begin{array}{c}18.8 \\
(\mathrm{SD}=3.7)\end{array}$ & $\begin{array}{c}17.9 \\
(\mathrm{SD}=4.71)\end{array}$ & $\begin{array}{l}F(2)=2.4 \\
p>0.05\end{array}$ & $\begin{array}{l}t(67)=1.0 \\
p>0.05\end{array}$ & $\begin{array}{l}t(67)=2.1 \\
p<0.05\end{array}$ \\
\hline $\begin{array}{l}\text { Influence Over } \\
\text { Decisions } \\
(\mathrm{N}=69)\end{array}$ & $\begin{array}{l}\text { Range: } 3-16 \\
\text { Mean } 11.5 \\
\text { SD }=2.9\end{array}$ & $\begin{array}{c}11.6 \\
(\mathrm{SD}=2.3)\end{array}$ & $\begin{array}{c}12.4 \\
(\mathrm{SD}=2.01)\end{array}$ & $\begin{array}{c}10.7 \\
(\mathrm{SD}=4.2)\end{array}$ & $\begin{array}{l}F(2)=1.14 \\
p>0.05\end{array}$ & $\begin{array}{l}t(67)=-1.3 \\
p>0.05\end{array}$ & $\begin{array}{l}t(67)=-0.3 \\
p>0.05\end{array}$ \\
\hline $\begin{array}{l}\text { Role Clarity } \\
(\mathrm{N}=68)\end{array}$ & $\begin{array}{l}\text { Range: } 2-20 \\
\text { Mean }=14.3 \\
\mathrm{SD}=3.2\end{array}$ & $\begin{array}{c}14.3 \\
(\mathrm{SD}=2.8)\end{array}$ & $\begin{array}{c}13.9 \\
(\mathrm{SD}=2.7)\end{array}$ & $\begin{array}{c}14.6 \\
(S D=4.2)\end{array}$ & $\begin{array}{l}F(2)=0.15 \\
p>0.05\end{array}$ & $\begin{array}{l}t(66)=0.4 \\
p>0.05\end{array}$ & $\begin{array}{l}t(66)=0.1 \\
p>0.05\end{array}$ \\
\hline $\begin{array}{l}\text { Role Conflict } \\
(\mathrm{N}=67)\end{array}$ & $\begin{array}{l}\text { Range: } 0-12 \\
\text { Mean }=3.6 \\
\mathrm{SD}=3.5\end{array}$ & $\begin{array}{c}3.7 \\
(\mathrm{SD}=3.4)\end{array}$ & $2.8(\mathrm{SD}=1.5)$ & $3.8(\mathrm{SD}=4.4)$ & $\begin{array}{l}F(2)=0.29 \\
p>0.05\end{array}$ & $\begin{array}{l}t(67)=0.25 \\
p>0.05\end{array}$ & $\begin{array}{l}t(67)=-0.3 \\
p>0.05\end{array}$ \\
\hline $\begin{array}{l}\text { Supervisor } \\
\text { Support } \\
(\mathrm{N}=67)\end{array}$ & $\begin{array}{l}\text { Range: } 0-8 \\
\text { Mean }=6.36 \\
S D=1.62\end{array}$ & $\begin{array}{c}6.4 \\
(\mathrm{SD}=1.45)\end{array}$ & $\begin{array}{c}6.2 \\
(\mathrm{SD}=1.72)\end{array}$ & $\begin{array}{c}6.3 \\
(\mathrm{SD}=1.94)\end{array}$ & $\begin{array}{l}F(2)=0.11 \\
p>0.05\end{array}$ & $\begin{array}{l}t(67)=-0.1 \\
p>0.05\end{array}$ & $\begin{array}{l}t(67)=-0.4 \\
p>0.05\end{array}$ \\
\hline $\begin{array}{l}\text { Peer Support } \\
(\mathrm{N}=67)\end{array}$ & $\begin{array}{l}\text { Range: } 4-16 \\
\text { Mean }=12.2 \\
S D=2.9\end{array}$ & $\begin{array}{c}12.1 \\
(\mathrm{SD}=2.7)\end{array}$ & $\begin{array}{c}13.1 \\
(\mathrm{SD}=1.8)\end{array}$ & $\begin{array}{c}11.7 \\
(\mathrm{SD}=3.8)\end{array}$ & $\begin{array}{l}F(2)=0.77 \\
p>0.05\end{array}$ & $\begin{array}{l}t(67)=-0.7 \\
p>0.05\end{array}$ & $\begin{array}{l}t(67)=-0.2 \\
p>0.05\end{array}$ \\
\hline
\end{tabular}




\begin{tabular}{|l|l|c|c|c|l|l|l|}
\hline $\begin{array}{l}\text { Work } \\
\begin{array}{l}\text { Satisfaction } \\
(\mathrm{N}=66)\end{array}\end{array}$ & $\begin{array}{l}\text { Range: } 12-24 \\
\text { Mean =19.3 }\end{array}$ & $\begin{array}{c}19.1 \\
\mathrm{SD}=2.1\end{array}$ & $\begin{array}{c}20.1 \\
(\mathrm{SD}=1.9)\end{array}$ & $\begin{array}{c}19.3 \\
(\mathrm{SD}=2.4)\end{array}$ & $\begin{array}{l}\mathrm{F}(2)=0.88 \\
\mathrm{p}>0.05\end{array}$ & $\begin{array}{l}t(64)=0.9 \\
\mathrm{p}>0.05\end{array}$ & $\begin{array}{l}t(64)=0.0 \\
\mathrm{p}>0.05\end{array}$ \\
\hline
\end{tabular}


Table 3: Key-DAB Coding frameworks for Keyworking Duties and Boundaries (Key-DAB) Scale (N = 57)

\begin{tabular}{|c|c|c|c|c|}
\hline $\begin{array}{l}\text { Instructions: } \\
\text { In this section, you are ask } \\
\text { service user to be the respo } \\
\text { Please tick the one box you }\end{array}$ & $\begin{array}{l}\text { to say whether yo } \\
\text { bility of their Key } \\
\text { ink best identifies }\end{array}$ & $\begin{array}{l}\text { believe certain d } \\
\text { orker, of the staff } \\
\text { vho is responsible }\end{array}$ & $\begin{array}{l}\text { ties in service of a } \\
\text { eam as a whole, } o \\
\text { or fulfilling this } d t\end{array}$ & $\begin{array}{l}\text { individual } \\
\text { f management. }\end{array}$ \\
\hline $\begin{array}{l}\text { e.g.: } 1 \text {. Making medical } \\
\text { appointments for the } \\
\text { service user }\end{array}$ & $\begin{array}{l}\text { Total times } \\
\text { selected }\end{array}$ & $\begin{array}{l}\text { Binary Coding } \\
\text { "Sole" }\end{array}$ & $\begin{array}{l}\text { Binary Coding } \\
\text { "Any" }\end{array}$ & $\begin{array}{l}\text { Likert Scale } \\
\text { Coding }\end{array}$ \\
\hline Keyworker & $204(16.27 \%)$ & 1 & 1 & 2 \\
\hline $\begin{array}{l}\text { Keyworker with Staff } \\
\text { Team }\end{array}$ & $440(35.09 \%)$ & & 1 & 1 \\
\hline $\begin{array}{l}\text { Keyworker with } \\
\text { Manager }\end{array}$ & $400(31.9 \%)$ & 0 & 1 & 1 \\
\hline All Staff Members & $152(12.12 \%)$ & & 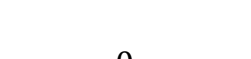 & . \\
\hline Manager & $46(3.67 \%)$ & & & \\
\hline Possible range & & $0-22$ & $0-22$ & $0-44$ \\
\hline Observed range & & $0-12$ & $0-22$ & $0-33$ \\
\hline Cronbach's Alpha & & 0.82 & 0.91 & 0.89 \\
\hline Mean (SD): & Total $(\mathrm{N}=57)$ & $3.58(3.74)$ & $14.19(5.98)$ & $17.51(8.09)$ \\
\hline Cur & nt KW $(\mathrm{N}=33)$ & $3.43(3.83)$ & $15.45(5.83)$ & $18.60(7.94)$ \\
\hline & ner KW $(\mathrm{N}=7)$ & $3.14(3.63)$ & $13.28(2.42)$ & $16.14(4.95)$ \\
\hline & er KW (N = 17) & $4.06(3.77)$ & $12.06(6.79)$ & $15.94(9.37)$ \\
\hline & lential $(\mathrm{N}=34)$ & $2.59(2.97)^{\alpha}$ & $12.71(5.55)^{\beta}$ & $15.09(6.54)^{\mu}$ \\
\hline Day & rvices $(\mathrm{N}=19)$ & $5.63(4.25)^{\alpha}$ & $17.84(4.51)^{\beta}$ & $23.26(6.84)^{\mu}$ \\
\hline High Ability Servi & Users $(\mathrm{N}=33)$ & $3.51(3.47)$ & $14.91(5.42)$ & $18.21(7.27)$ \\
\hline Low Ability Servi & Users $(\mathrm{N}=24)$ & $3.67(4.14)$ & $13.17(6.63)$ & $16.54(9.17)$ \\
\hline Predictive va & lity y & & & \\
\hline Relationship with Locus & f Control - KW & $-0.18(0.11)$ & $-0.20^{*}(0.10)$ & $-0.23^{*}(0.11)$ \\
\hline LOC Squared - KW & & $-0.05(0.06)$ & $-0.14^{*}(0.05)$ & $-0.12^{*}(0.05)$ \\
\hline LOC- Non-KW & & $-0.07(0.10)$ & $-0.06(0.12)$ & $-0.08(0.12)$ \\
\hline LOC Squared - Non-KW & & $-0.06(0.03)$ & $-0.05(0.03)$ & $-0.07(0.03)$ \\
\hline Predictive $\mathbf{u}$ & ity $y$ & & & \\
\hline Work Pressure & & $-0.51(0.28)$ & $-0.72 *(0.19)$ & $-0.45^{*}(0.01)$ \\
\hline & Squared & $0.04(0.03)$ & $0.02 *(0.01)$ & $0.01 *(0.00)$ \\
\hline Role Clarity & & $0.24(0.34)$ & $-0.39(0.25)$ & $-0.02(0.17)$ \\
\hline & Squared & $-0.03(0.03)$ & $0.02(0.01)$ & $0.00(0.00)$ \\
\hline Role Conflict & & $-0.05(0.41)$ & $-0.34(0.31)$ & $0.00(0.21)$ \\
\hline
\end{tabular}




\begin{tabular}{|c|c|c|c|c|}
\hline & Squared & $0.00(0.04)$ & $0.01(0.01)$ & $0.00(0.01)$ \\
\hline \multirow[t]{2}{*}{ Job Autonomy } & \multirow[b]{2}{*}{ Squared } & $-0.12(0.46)$ & $-0.70^{*}(0.34)$ & $-0.21(0.23)$ \\
\hline & & $0.00(0.04)$ & $0.03 *(0.01)$ & $0.00(0.01)$ \\
\hline \multirow[t]{2}{*}{ Peer Support } & \multirow[b]{2}{*}{ Squared } & $-0.28(0.31)$ & $0.30(0.22)$ & $0.22(0.15)$ \\
\hline & & $0.02(0.03)$ & $-0.01(0.01)$ & $-0.01(0.00)$ \\
\hline \multirow[t]{2}{*}{ Supervisor Support } & \multirow[b]{2}{*}{ Squared } & $0.21(0.18)$ & $0.01(0.14)$ & $0.09(0.09)$ \\
\hline & & $-0.02(0.02)$ & $0.00(0.01)$ & $0.00(0.00)$ \\
\hline \multirow[t]{2}{*}{ Influence Over Decisions } & \multirow[b]{2}{*}{ Squared } & $0.02(0.34)$ & $-0.21(0.25)$ & $0.01(0.17)$ \\
\hline & & $-0.01(0.03)$ & $0.01(0.01)$ & $0.00(0.00)$ \\
\hline
\end{tabular}

$* \mathrm{p}<0.05$

$\beta: t(51)-3.06 ; p<0.05 ; \mu: t(51)-4.29 ; p<0.05 ; \alpha: t(51)-3.45 ; p<0.05$;

$y$ : Ordinary Least Squares regression adjusting for Keyworking Experience and Day/Residential Setting 
Table 4: Experiences of the Keyworker Role $(N=49)$

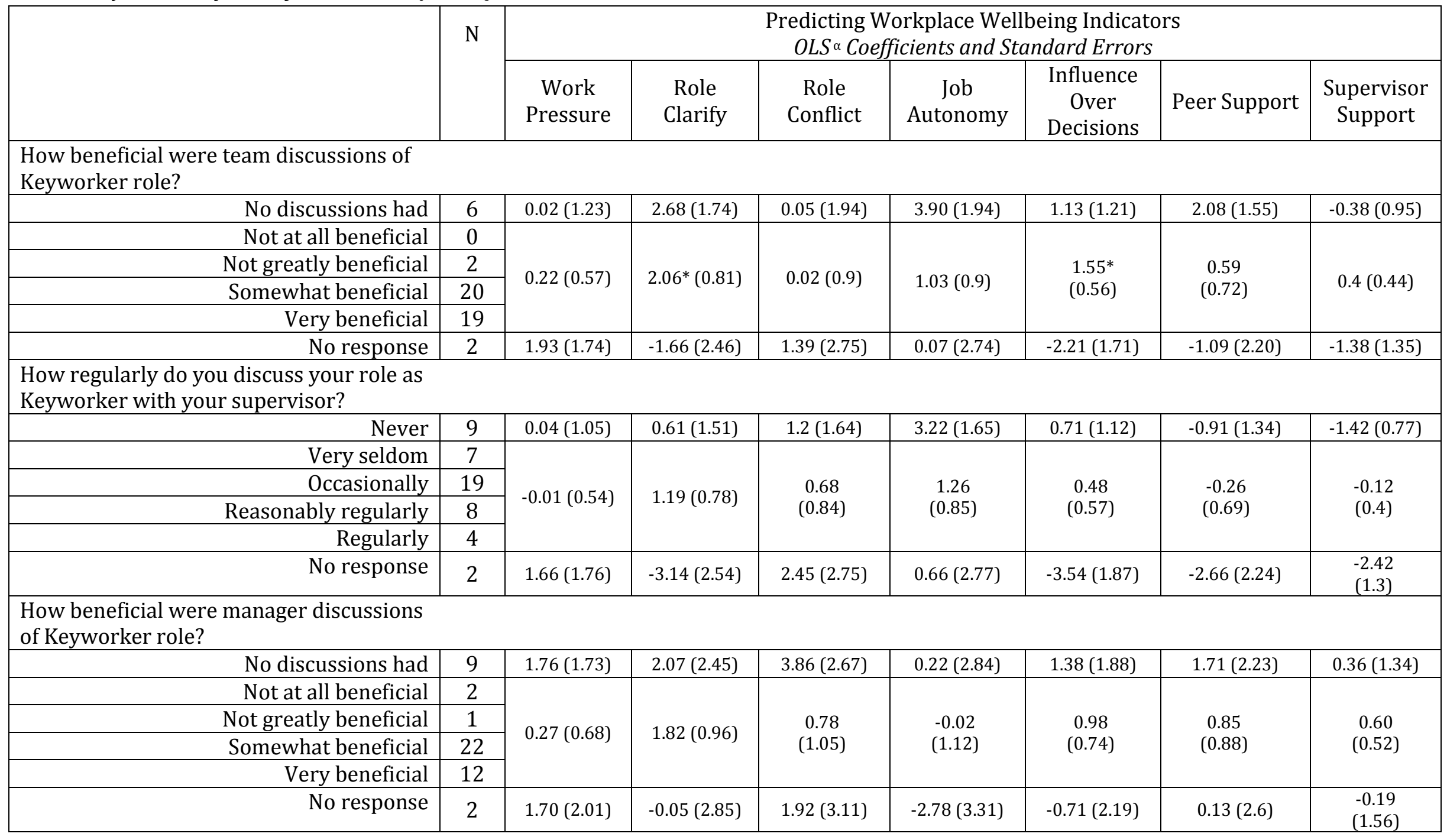


Do you enjoy a more positive relationship

with your Key Service User than with

other Service Users?

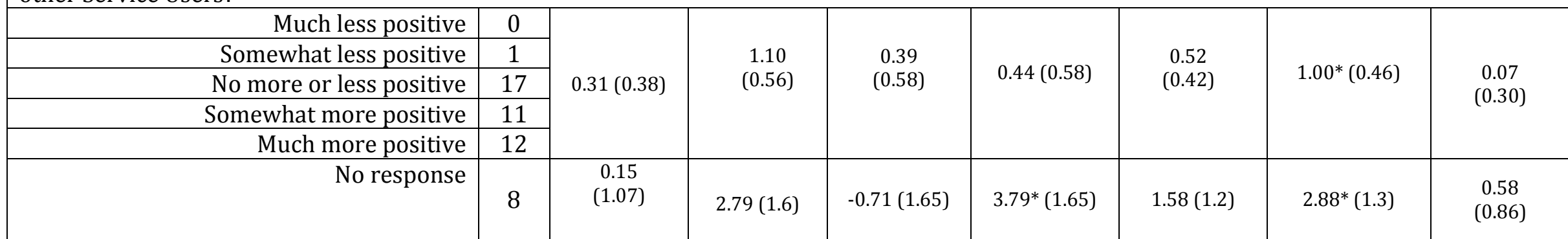

Do you enjoy a more positive relationship

with your Key Service User than other

staff members do?

\begin{tabular}{|c|c|c|c|c|c|c|c|c|}
\hline Much less positive & 0 & \multirow{5}{*}{$0.88(0.45)$} & \multirow{5}{*}{$1.1(0.71)$} & \multirow{5}{*}{$\begin{array}{c}0.82 \\
(0.71)\end{array}$} & \multirow{5}{*}{$0.81(0.72)$} & \multirow{5}{*}{$\begin{array}{c}0.77 \\
(0.52)\end{array}$} & \multirow{5}{*}{$\begin{array}{c}0.14 \\
(0.59)\end{array}$} & \multirow{5}{*}{$-0.2(0.37)$} \\
\hline Somewhat less positive & 1 & & & & & & & \\
\hline No more or less positive & 16 & & & & & & & \\
\hline Somewhat more positive & 20 & & & & & & & \\
\hline Much more positive & 5 & & & & & & & \\
\hline No response & 9 & $1.17(1.13)$ & $\begin{array}{c}1.87 \\
(1.78)\end{array}$ & $0.24(1.8)$ & $4.14 *(1.81)$ & $1.61(1.31)$ & $1.4(1.49)$ & $-0.13(0.94)$ \\
\hline
\end{tabular}

${ }^{*} \mathrm{p}<$ 0.05; $\alpha$ : Univariable Ordinary Least Squares Regression, separate terms entered for missing or not applicable values (e.g, "No discussions had") 
Figure 1: Key-DAB Items, Options and Coding:

\begin{tabular}{|c|c|c|c|c|c|}
\hline \multicolumn{6}{|c|}{$\begin{array}{l}\text { In this section, you are asked to say which of the following options you believe } \\
\text { best describes the person or group responsible for each of the following duties } \\
\text { pertaining to a service user's care: } \\
\text { Keyworker; Keyworker and staff team together; All staff members; Keyworker } \\
\text { and manager together; or Management }\end{array}$} \\
\hline \multicolumn{6}{|c|}{ Please tick the one box you think best identifies who is responsible for fulfilling this duty } \\
\hline & Keyworker & $\begin{array}{l}\text { Keyworker } \\
\text { and staff team } \\
\text { together }\end{array}$ & $\begin{array}{l}\text { All staff } \\
\text { members }\end{array}$ & $\begin{array}{l}\text { Keyworker } \\
\text { and manager } \\
\text { together }\end{array}$ & Management \\
\hline $\begin{array}{l}\text { 1. Making medical } \\
\text { appointments for } \\
\text { the client }\end{array}$ & & & & & \\
\hline \multicolumn{6}{|c|}{ Coding } \\
\hline $\begin{array}{c}\text { Binary Coding } \\
(K W-\text {-Sole })\end{array}$ & 1 & $\boldsymbol{0}$ & $\boldsymbol{O}$ & $\boldsymbol{0}$ & 0 \\
\hline $\begin{array}{c}\text { Binary Coding } \\
\text { (KW-Any) }\end{array}$ & 1 & 1 & 0 & 1 & $\boldsymbol{O}$ \\
\hline Likert Coding & 2 & 1 & $\boldsymbol{O}$ & 1 & $\boldsymbol{O}$ \\
\hline
\end{tabular}


Figure 2: Fitted values: Key-DAB vs Locus of Control, Job Autonomy, Work Pressure
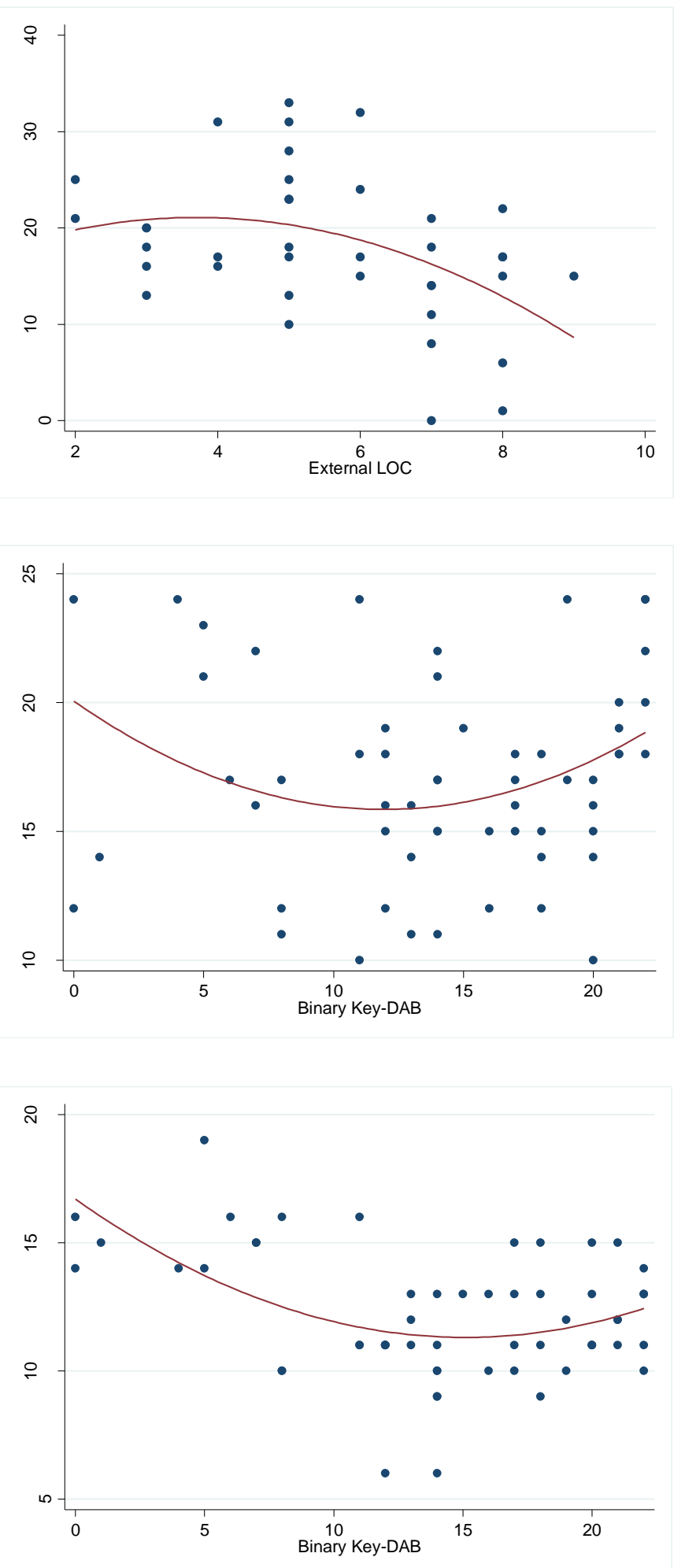